\title{
Full-Length Genomic Sequence of Subgenotype IIIA Hepatitis A Virus Isolate in Republic of Korea
}

\author{
Ah-Ra Lee, ${ }^{1}$ Sung-Geun Lee, ${ }^{2}$ Lae-Hyung Kang, \\ Weon-Hwa Jheong, ${ }^{3}$ and Soon-Young Paik ${ }^{1}$ \\ ${ }^{1}$ Department of Microbiology, College of Medicine, The Catholic University of Korea, Seoul 137-701, Republic of Korea \\ ${ }^{2}$ Korea Zoonosis Research Institute, Chonbuk National University, Jeonju 561-756, Republic of Korea \\ ${ }^{3}$ Environmental Infrastructure Research Department, National Institute of Environmental Research, \\ Incheon 404-708, Republic of Korea
}

Correspondence should be addressed to Soon-Young Paik; paik@catholic.ac.kr

Received 28 February 2013; Revised 28 May 2013; Accepted 31 May 2013

Academic Editor: Fumio Imazeki

Copyright (C) 2013 Ah-Ra Lee et al. This is an open access article distributed under the Creative Commons Attribution License, which permits unrestricted use, distribution, and reproduction in any medium, provided the original work is properly cited.

\begin{abstract}
Hepatitis A virus is known to cause acute hepatitis and has significant implications for public health throughout the world. In the Republic of Korea, the number of patients with hepatitis A virus infection has been increasing rapidly since 2006. In this study, the Kor-HAV-F strain was identified as subgenotype IIIA by RT-PCR, and its identity was confirmed by nucleotide sequencing and alignment analysis. Moreover, detailed phylogenetic analysis indicated that the Kor-HAV-F strain clustered into subgenotype IIIA, including strains isolated in Japan, Norway, and India. The entire amino acid sequence of the VP1 and 2A regions was compared with that of the reference strains isolated in various countries. We found 2 amino acid changes (T168A and L96P, resp.) in the VP1 and $2 \mathrm{~A}$ regions, which had not been found in any other hepatitis A virus strain. To our knowledge, this study is the first to report the full-length sequence of a hepatitis A virus isolated in the Republic of Korea.
\end{abstract}

\section{Introduction}

Hepatitis A virus (HAV), known to cause acute hepatitis, has significant implications for public health worldwide. HAV infection is endemic in developing countries, including Thailand, India, and Mexico. In contrast, industrialized countries have a decreasing exposure rate to HAV, due to improvements in hygiene and sanitation conditions [1]. Direct person-toperson spread by the fecal/oral route is the most important mean of transmission of hepatitis A, and infection with HAV can cause sporadic and epidemic acute hepatitis in humans $[2,3]$.

HAV is the only member of the genus Hepatovirus within the family Picornaviridae [4]. The positive-sense singlestranded RNA consists of a highly conserved $5^{\prime}$-nontranslated region (NTR), a single open reading frame (ORF) encoding a polyprotein, and a $3^{\prime}$-NTR $[4,5]$. The single ORF is divided into 3 functional regions, namely, P1, P2, and P3. The $\mathrm{P} 1$ region encodes the capsid polypeptides VP4, VP2,
VP3, and VP1, whereas P2 and P3 encode the nonstructural polypeptides (2A-2C and 3A-3D, resp.) [6].

Thus far, HAV strains have been classified into 3 human and simian genotypes (I-VI), of which genotypes I, II, and III are found in humans; these genotypes are further divided into subgenotypes IA and IB, IIA and IIB, and IIIA and IIIB, respectively $[7,8]$. Most of the human HAV strains belong to genotypes I and III [8-10]. An HAV genotype is defined as a group of viruses with $>85 \%$ nucleotide sequence identity. The HAV genotypes are further classified into subgenotypes with sequence variability of $<7.5 \%$ [11].

Subgenotypes IA and IB are most often reported in Brazil, France, China, and Japan [12-14]. Subgenotype IA is the most common type worldwide, whereas subgenotype IB has been prevalent in the regions of Europe, Australia, and Mediterranean [15-18]. Subgenotype IIIA has been found in various countries in Asia, Europe, and USA, while subgenotype IIIB was found to be responsible for some cases of HAV infection in Denmark and Japan [9, 13, 19-23]. 
TABLE 1: Primer sets used in this study.

\begin{tabular}{|c|c|c|c|c|}
\hline & Primer & Sequence $\left(5^{\prime} \rightarrow 3^{\prime}\right)$ & Polarity & Region \\
\hline \multirow{2}{*}{ Diagnosis primer sets } & HAV-F & GGT TTC TAT TCA GAT TGC AAA TTA & + & $2873-2889$ \\
\hline & HAV- R & AGT AAA AAC TCC AGC ATC CAT TTC & - & $3357-3380$ \\
\hline \multirow{26}{*}{ Designed primer sets } & HAV-1F & GCC TAG GCT ATA GGC TAA AT & + & $79-98$ \\
\hline & HAV-1R & CGT TCC CAA CAT CTG TGT & - & $304-321$ \\
\hline & HAV-2F & GTT GTA AAT ATT AAT TCC TGC AGG & + & $124-147$ \\
\hline & HAV-2R & CAG ACA ATC CAC TTA ATG CAT & - & $510-530$ \\
\hline & HAV-3F & CTA TGA AGA GAT GCT TTG GAT & + & $412-432$ \\
\hline & HAV-3R & TGT ATC TCA ATT CCA AAT CTT GC & - & 1095-1117 \\
\hline & $\mathrm{HAV}-4 \mathrm{~F}$ & ATT CAT TCT GCT GAY TGG TTG & + & $972-992$ \\
\hline & $\mathrm{HAV}-4 \mathrm{R}$ & CAA CTG GRA TAA CCT TGA TCT & - & $1675-1695$ \\
\hline & HAV-5F & AGG AAG ATT GGA AAT CTG ATG & + & 1549-1569 \\
\hline & HAV-5R & TTC ACT GTT GTA ATR CCA ACT TG & - & $2253-2275$ \\
\hline & HAV-6F & CAA GTT GGC ATT ACA ACA GTG & + & $2253-2273$ \\
\hline & HAV-6R & GAG CAA TTC TAT CCA TCA TTG & - & $3010-3030$ \\
\hline & HAV-7F & GAA ATG GAT GCT GGA GTT TTT ACT & + & $3357-3380$ \\
\hline & HAV-7R & CTG AAC ARA TAT CYC TAA GCC & - & $3991-4011$ \\
\hline & $\mathrm{HAV}-8 \mathrm{~F}$ & GTT GAG AGT GAT GAA TTA TGC & + & $3851-3871$ \\
\hline & HAV-8R & YTG TCC ACT ATA TCC ATC CCA & - & $4521-4541$ \\
\hline & HAV-9F & AAT GGT GMC AAG ATG TGA GCC & + & $4364-4384$ \\
\hline & HAV-9R & AAC TGC AAC CCA CTT RTG RTT & - & $5091-5111$ \\
\hline & $\mathrm{HAV}-10 \mathrm{~F}$ & GGG ATT ATC AGA TGA TGA CAA & + & $4982-5002$ \\
\hline & HAV-10R & TAC CTC TCC ARG CTT GAT CAA & - & $5743-5763$ \\
\hline & HAV-11F & GGA CTC CAA TGT TAA TTT CAG & + & $5647-5667$ \\
\hline & HAV-11R & TCC ATA TTR ATT GCA TCT ATC CC & - & $6234-6256$ \\
\hline & $\mathrm{HAV}-12 \mathrm{~F}$ & GAT GAG CCA GAT GAT TAT AAA GA & + & $6120-6142$ \\
\hline & $\mathrm{HAV}-12 \mathrm{R}$ & AGA AGG CAT TGA MCC ACA TAC & - & $6819-6839$ \\
\hline & HAV-13F & GTA TGT GGK TCA ATG CCT TCT & + & $6819-6839$ \\
\hline & HAV-13R & WAT TTA CTG AAA AGA YAA AAT AAA CAA AC & - & $7436-7466$ \\
\hline
\end{tabular}

Previouse studies on HAV genotypes in Republic of Korea have shown a distinct changing pattern in circulating HAV genotypes over the past 10 years [24]. Until 2004, subgenotype IA was the most prevalent in the Republic of Korea [25]. However, studies conducted between 2004 and 2008 reported the cocirculation of the 2 prevalent subgenotypes IA and IIIA $[22,25,26]$. Subgenotype IIIA has been the predominant subgenotype since 2008, according to a previous study [22, 26].

In this study, the whole genome sequence of a South Korean HAV subgenotype IIIA isolate was analyzed and compared with that of available reference strains to determine the genetic relationship along the entire genome in the Republic of Korea.

\section{Material and Methods}

2.1. Stool Sample Collection. An HAV-positive stool sample was isolated from a 35-year-old female patient with fever and myalgia, in Seoul, the Republic of Korea, in October 2011. The sample was obtained from the Waterborne Virus Bank (Seoul, the Republic of Korea). The stool sample was stored at $-70^{\circ} \mathrm{C}$.

2.2. Viral RNA Extraction. The stool sample was diluted to a ratio of $1: 10$ in phosphate buffered saline (PBS), mixed, and centrifuged. From $140 \mu \mathrm{L}$ of this diluted stool sample, viral RNA was extracted using a QIAamp viral RNA mini kit (Qiagen, Hilden, Germany) according to the manufacturer's instructions. A $50-\mu \mathrm{L}$ volume of elute was obtained and stored at $-70^{\circ} \mathrm{C}$ until analysis.

2.3. Reverse Transcription-PCR (RT-PCR). For the detection of HAV, reverse transcription polymerase chain reaction (RTPCR) was performed with a OneStep RT-PCR Kit (Qiagen, Hilden, Germany), with HAV-F and HAV-R primers based on the sequence of the VP1-2A junction region (Table 1). To facilitate sequencing of the entire genome of the detected HAV strain, RT-PCR was performed with the OneStep RTPCR Kit (Qiagen, Hilden, Germany), with 13 pairs of newly designed primer sets (Table 1). We used $5 \mu \mathrm{L}$ of viral RNA as template and $20 \mu \mathrm{L}$ of the premixed kit solution. The PCR was carried out in a PCR System S1000 thermal cycler (BIO-RAD, CA, USA) according to the following protocol: an initial RT step at $50^{\circ} \mathrm{C}$ for $30 \mathrm{~min}$, followed by PCR activation at $95^{\circ} \mathrm{C}$ for $15 \mathrm{~min}$ and 40 cycles of amplification, each consisting of $1 \mathrm{~min}$ at $95^{\circ} \mathrm{C}, 1 \mathrm{~min}$ at $52^{\circ} \mathrm{C}$ to $54^{\circ} \mathrm{C}$, and $1 \mathrm{~min}$ at $72^{\circ} \mathrm{C}$, with a final extension step of $10 \mathrm{~min}$ at $72^{\circ} \mathrm{C}$. The PCR products were then electrophoresed on a $2 \%$ ethidium bromide-stained agarose gel.

2.4. Cloning and Sequencing of RT-PCR Products. The amplified fragments were purified from the gel using the HiYield 
Gel/PCR DNA Extraction Kit (RBC, Taipei, Taiwan). These products were then cloned into the pGEM-T Easy Vector (Promega, Madison, WI, USA) according to the manufacturer's recommendations and transformed into competent E. coli $\mathrm{DH} 5 \alpha$ cells (RBC, Taipei, Taiwan). Transformants were selected on Luria-Bertani (LB) agar media (Duchefa, Haarlem, The Netherlands) containing $50 \mu \mathrm{g} / \mathrm{mL}$ ampicillin. Clones were expanded overnight at $37^{\circ} \mathrm{C}$ in $2 \mathrm{~mL} \mathrm{LB}$ media containing $50 \mu \mathrm{g} / \mathrm{mL}$ ampicillin, centrifuged at $4^{\circ} \mathrm{C}$ for $10 \mathrm{~min}$ at $800 \times \mathrm{g}$, resuspended in $600 \mu \mathrm{L}$ fresh LB media with $10 \%$ glycerol, and stored at $-80^{\circ} \mathrm{C}$ until required for further use. Plasmid DNA was purified using the HiYield Plasmid Mini Kit (RBC, Taipei, Taiwan) according to the manufacturer's recommendations. DNA was sequenced by Cosmo Genetech (Seoul, the Republic of Korea).

2.5. Sequence and Phylogenetic Analysis. The sequence data of the composite sequences of the 13 plasmids were aligned using the Clustal W method with the DNASTAR software (DNAStar, Inc., Madison, WI, USA) and CLC Main Workbench Program version 6.7.1 (CLC Bio, Katrinebjerg, Denmark) to obtain the entire genome sequence. Dendrograms were constructed using the neighbor-joining method with MEGA software version 4.0.

2.6. Nucleotide Sequence Accession Number. The nucleotide sequence of the HAV-positive stool sample isolate was submitted to the GenBank database under the following accession no.: JQ655151.

\section{Results and Discussion}

Globally, 1.4 million of patients affected by HAV infection have been reported annually. The prevalence rate of HAV in different countries varies with income and hygiene levels. According to data from Korea Centers for Disease Control and Prevention (KCDC), HAV infection in the Republic of Korea has been increasing consistently since 2001. Moreover, the number of patients with HAV infection has increased more rapidly since 2006. In 2009, the number of patients with HAV infection was approximately 143 times higher than that in 2001.

Generally, HAV IA was known as major subgenotype in the Republic of Korea. In 1994, 100\% of HAV strains were subgenotype IA although this prevalence significantly decreased from year to year, reaching $0 \%$ in 2008 , whereas HAV IIIA was first detected in 2005 and exhibited a peak prevalence of 100\% in the Republic of Korea in 2006 [22, 2528]. However, the 2 prevalent subgenotypes IA and IIIA cocirculated in the Republic of Korea since 2005 [25]. The difference in circulating subgenotypes differs depending on the region and period. Furthermore, 5 outbreaks associated with HAV infection occurred since 2005. Among them, 3 outbreaks were associated with subgenotype IIIA [29]. Despite their clear importance, complete genome analysis of subgenotype IIIA has not been yet reported in the Republic of Korea.

In this study, we examined the nucleotide and amino acid similarities and phylogenetic tree analysis between the partial and complete sequences of HAV reference strains. The KorHAV-F isolate had a genomic length of 7386 nucleotides (nt), excluding the poly(A) tract at the $3^{\prime}$ terminus, and was similar to those of the reported HAV isolates for which the entire genomic sequence is known. Moreover, the isolate possessed a single long ORF of $6684 \mathrm{nt}$ that encoded a polyprotein of 2228 amino acids. The single ORF was divided into 3 functional regions termed P1 (2373 nt), P2 (1893 nt), and P3 (2418 nt).

To assess the genetic relationship between the Kor-HAV-F strain and the other reference strains isolated worldwide, the sequences of the ORFs and the whole genomes were subjected to multiple sequence alignment analysis and phylogenetic analysis (Table 2). Sequence comparison with 33 known HAV isolates revealed that the Kor-HAV-F strain shares the greatest identity with the NOR-21 HAV strain (AJ299464), which was isolated from Norway, with $98.8 \%$ identity at nucleotide and 99.9\% identity at amino acid sequence levels. The Kor-HAVF strain clustered with the NOR-21, HA-JNG04-90F, and CPIND strains in a monophyletic branch. The 3 and 2 strains were isolated from India and Japan, respectively, belonged to 2 distinct clusters within subgenotype IIIA. The identities of the Kor-HAV-F strain with other subgenotypes (1A, IB, IIA, IIB, IIIB, and V) were within the range of $80.6-88.6 \%$ (nucleotide identity) and 92-98.5\% (amino acid identity), respectively (Figure 1(a)). Similarly, in the phylogenetic analysis of the P1 and P2 regions, the Kor-HAV-F strain clustered with those strains (Figures $1(\mathrm{~b})$ and $1(\mathrm{c})$ ). However, in the case of the P3 region, the Kor-HAV-F strain clustered with the NOR-21 and HA-JNG04-90F strains in a monophyletic branch (Figure 1(d)). Partial phylogenetic analysis of P3A indicated that the Kor-HAV-F strain clustered with only the NOR-21 strain in a monophyletic branch (Figure 1(e)).

Additionally, to assess the genetic relationship between Kor-HAV-F and the Korean strains, the sequences of the VP3/VP1 and VP1/2A junctions were subjected to multiple sequence alignment and phylogenetic analysis. In the case of VP3/VP1, sequence comparisons revealed that the Kor-HAVF strain shares the greatest identity with the NOR-21 strain (96.7\% nucleotide identity), whereas sequence identity with the Korean strains was relatively low (92.9-93.4\% nucleotide identity). These Korean strains belonged to a distinct cluster within the subgenotype IIIA (Figure 2(a)). In the case of VP1/2A, sequence comparisons revealed that the Kor-HAVF strain shares the greatest identity with the 21 (FJ372963) strain isolated in 2005 (98.8\% nucleotide identity). The KorHAV-F strain clustered with the Korean strains, other than the Korean and Japan strains, in a monophyletic branch (Figure 2(b)).

Nucleotide and amino acid identities between Kor-HAV$\mathrm{F}$ and representatives of each genotype are shown in Table 1. Kor-HAV-F sequence identity with the other genotypes was in the range of $79 \%-89.8 \%$, except for subgenotype IIIA in the coding region $\mathrm{P} 1-\mathrm{P} 3$, whereas amino acid sequences differed to a greater extent (89.4-99.1\% identity). Compared with subgenotype IA, Kor-HAV-F showed higher identity (82.8$83.3 \%$ at nucleotide level; $92.3-97 \%$ at amino acid level) with the H2 strain (isolated in 2007, subgenotype IA) than with the GBM strain, isolated in 1976, (81.7-83.1\% at nucleotide 


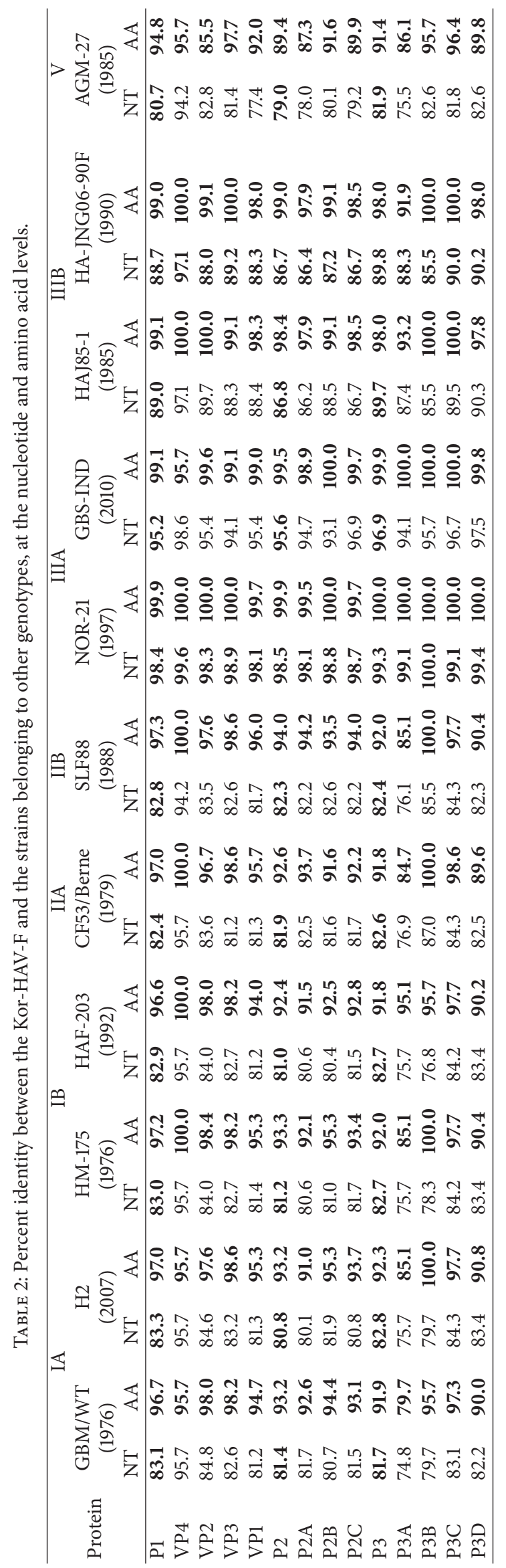




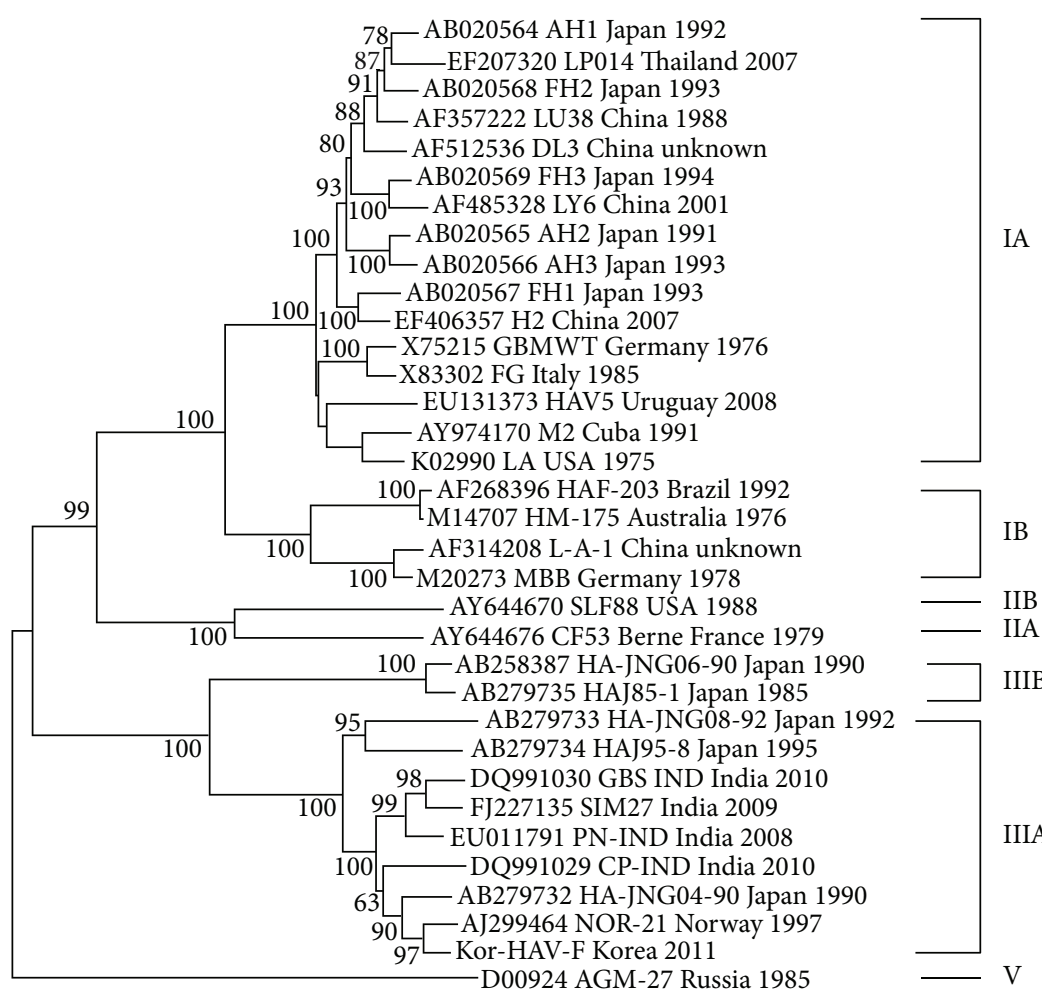

(a)

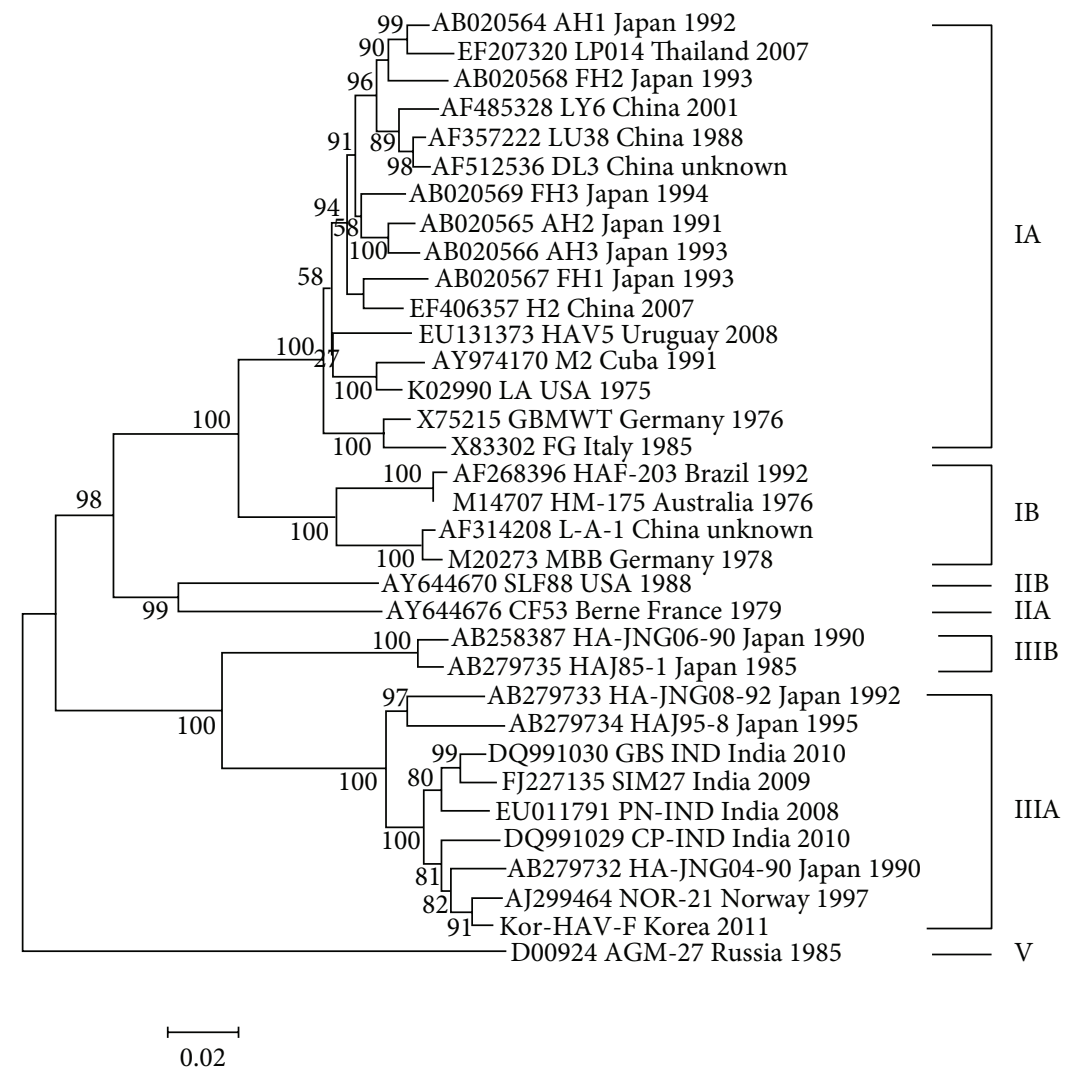

(b)

Figure 1: Continued. 


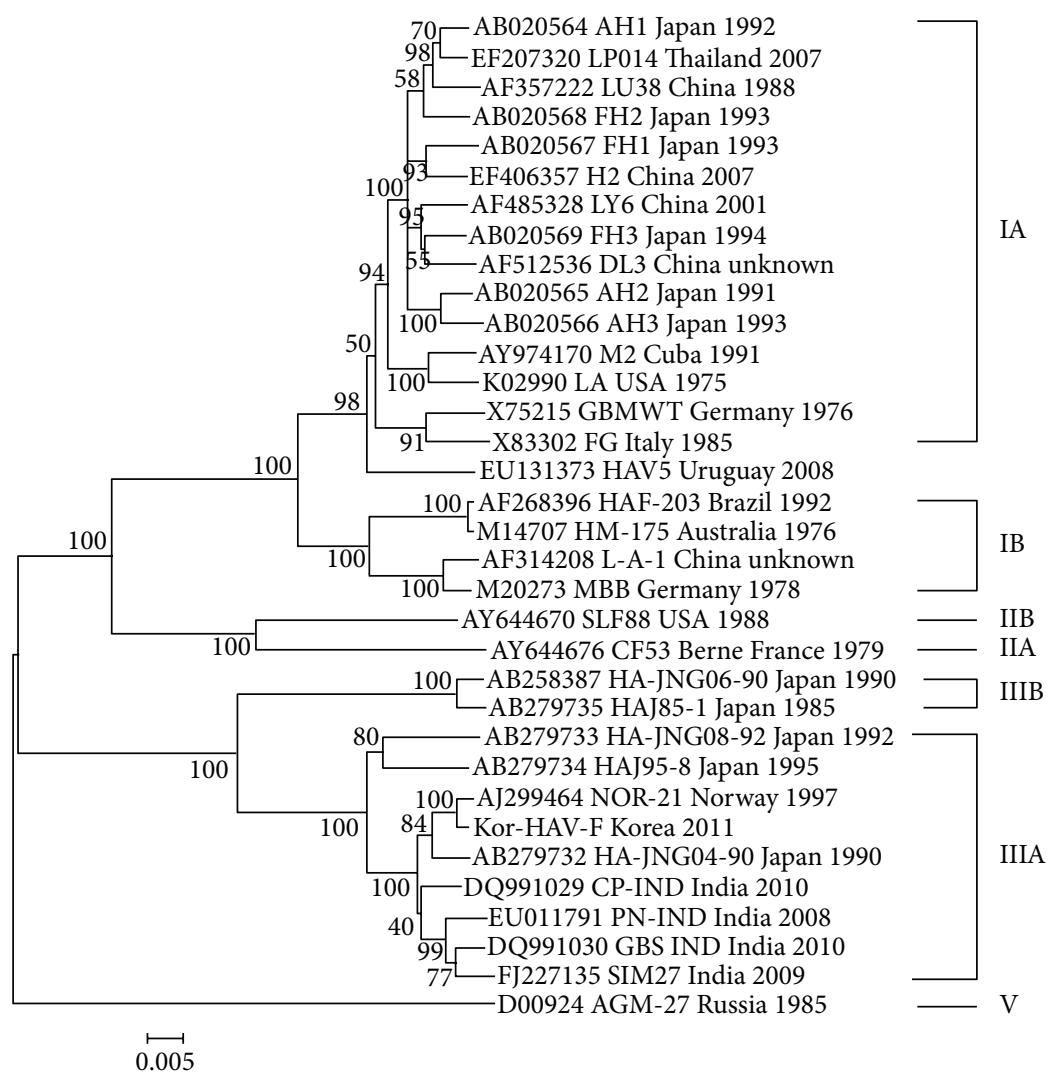

(c)

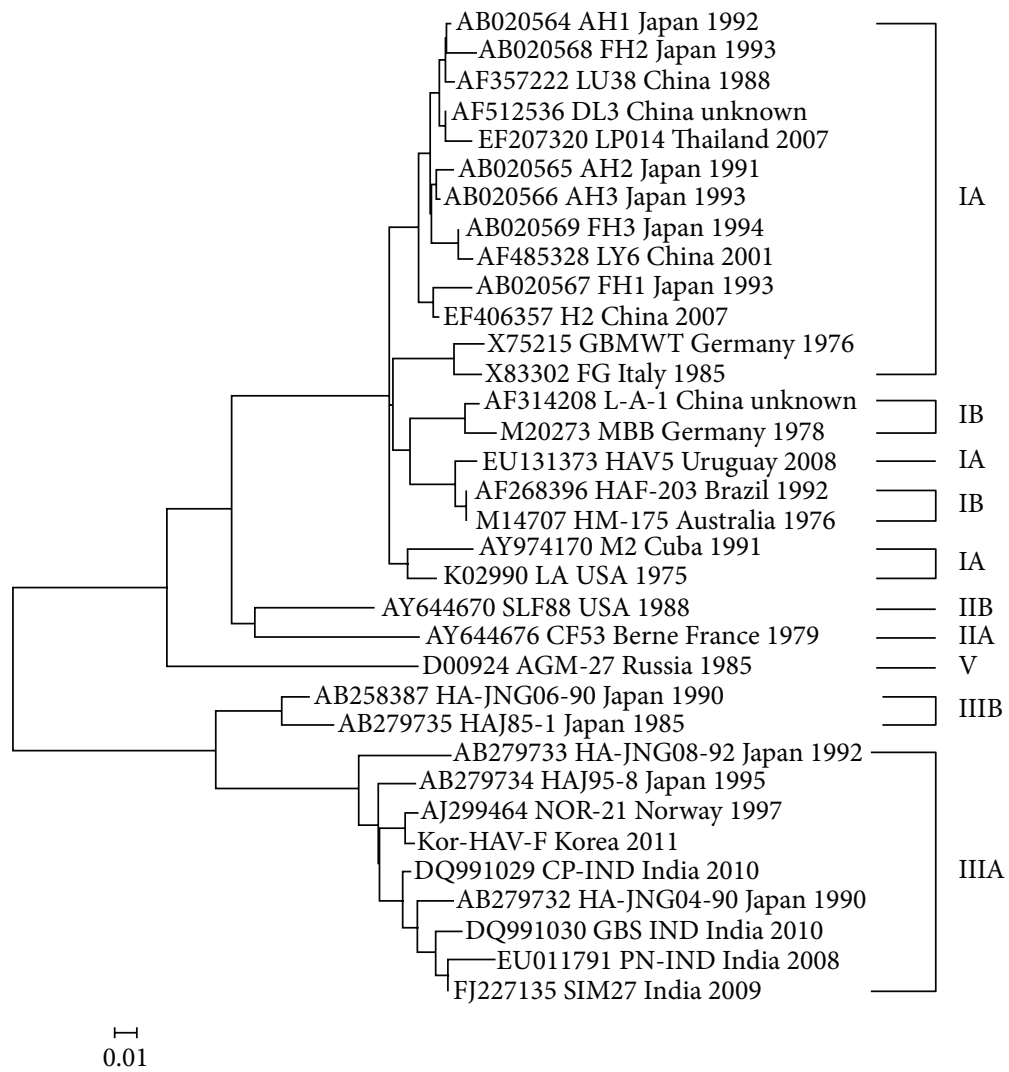

(d)

Figure 1: Continued. 


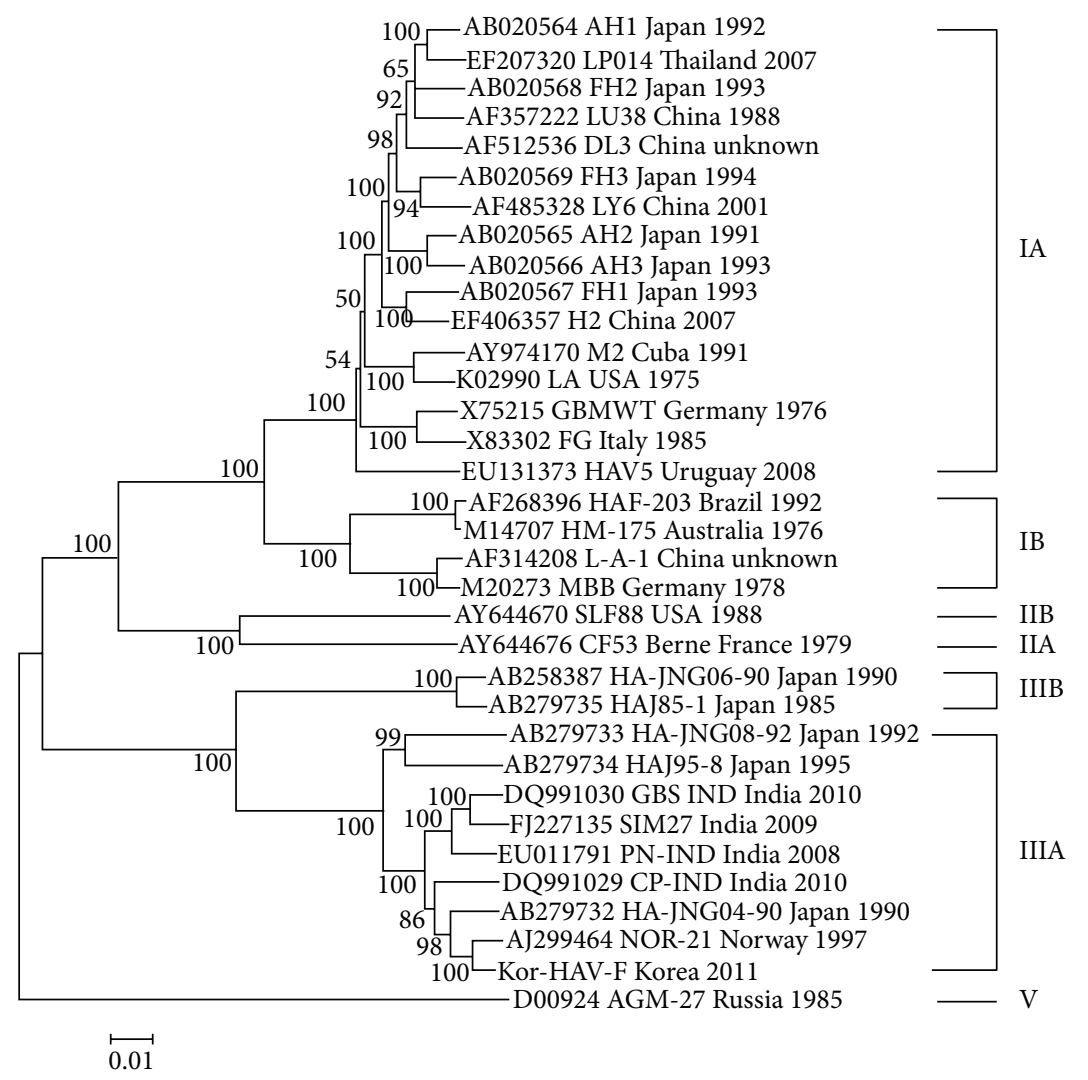

(e)

Figure 1: Phylogenetic trees of the nucleotide sequences of HAVs. The phylogenetic tree analysis was based on the nucleotide sequence 3 of the entire genomic region (a), P1 region (b), P2 region (c), P3 region (d), and P3A region (e) of the Kor-HAV-F and reference strains.

level; 91.9-96.7\% at amino acid level), at coding regions $\mathrm{P} 1$ and P3. However, Kor-HAV-F showed higher identity with the older strains than with the recent strains belonging to the subgenotype IB. Among the P1-P3 coding regions, the P3A site had the highest variability at nucleotide and amino acid levels.

Amino acid sequences of the VP1 region (300 amino acids) were compared with diverse subgenotype strains reported from various countries, including the Republic of Korea. The Kor-HAV-F strain showed a distinct substitution of Asn instead of Thr at position 168, which was not found in any other subgenotype. The Kor-HAV-F strain showed 92-99.7\% amino acid variation within the $\mathrm{P} 1$ region. Only the Kor-HAV-F strain, including subgenotypes IIIA, showed 2 amino acid changes (K34R and V42I) in the P1 region. Furthermore, genotypes III commonly showed 10 amino acid changes (E15K, I/M28L/V, R37Q, S266T, L270 M, T272S, S274T, S277D, A281L, and R298 K; Figure 2(a)). Inconsistent with previous reports, we found 12 amino acid changes in the VP1 region, but consistent with previous reports for other HAV subgenotype IIIA strains, our results also showed the existence of C-terminus cleavage sites as Leu 264/265 Asn, Glu 273/274 Thr, and Glu 285/286 Ser in the HAV VP1 protein (Figure 3(a)).
In the case of the $2 \mathrm{~A}$ region (189 amino acids), amino acid sequences were compared with diverse subgenotypes reported from various countries. The Kor-HAV-F strain showed a distinct substitution of Phe for Leu at position 96, which was not found in any other subgenotype. The KorHAV-F strain showed $87.3-99.5 \%$ amino acid variation within the P1 region. Only the Kor-HAV-F strain, including subgenotypes IIIA, showed a single amino acid change (S/C148A) in the $2 \mathrm{~A}$ region. Furthermore, genotype III commonly showed 8 amino acid changes (K/M/V39I, L42V, E55D, R64 K, L/V66I, D150E, V183I, and Q189 K). In particularly, genotypes II and III showed a single amino acid change at N/Y128H (Figure 3(b)).

In the Republic of Korea, 4 patients with HAV subgenotype IIIA have travelled overseas before the onset of symptoms, according to a previous study. Similarly, the HAV patient in this study had visited Taiwan before the onset of symptoms. Moreover, we found 2 novel amino acid changes that had not been reported in Korea earlier. Hence, it is assumed that this patient probably acquired the virus in Taiwan.

Korea, until the 1980s, was classified as a high endemic country, and most infections occurred in childhood. However, opportunities of infections for exposure decreased, with 


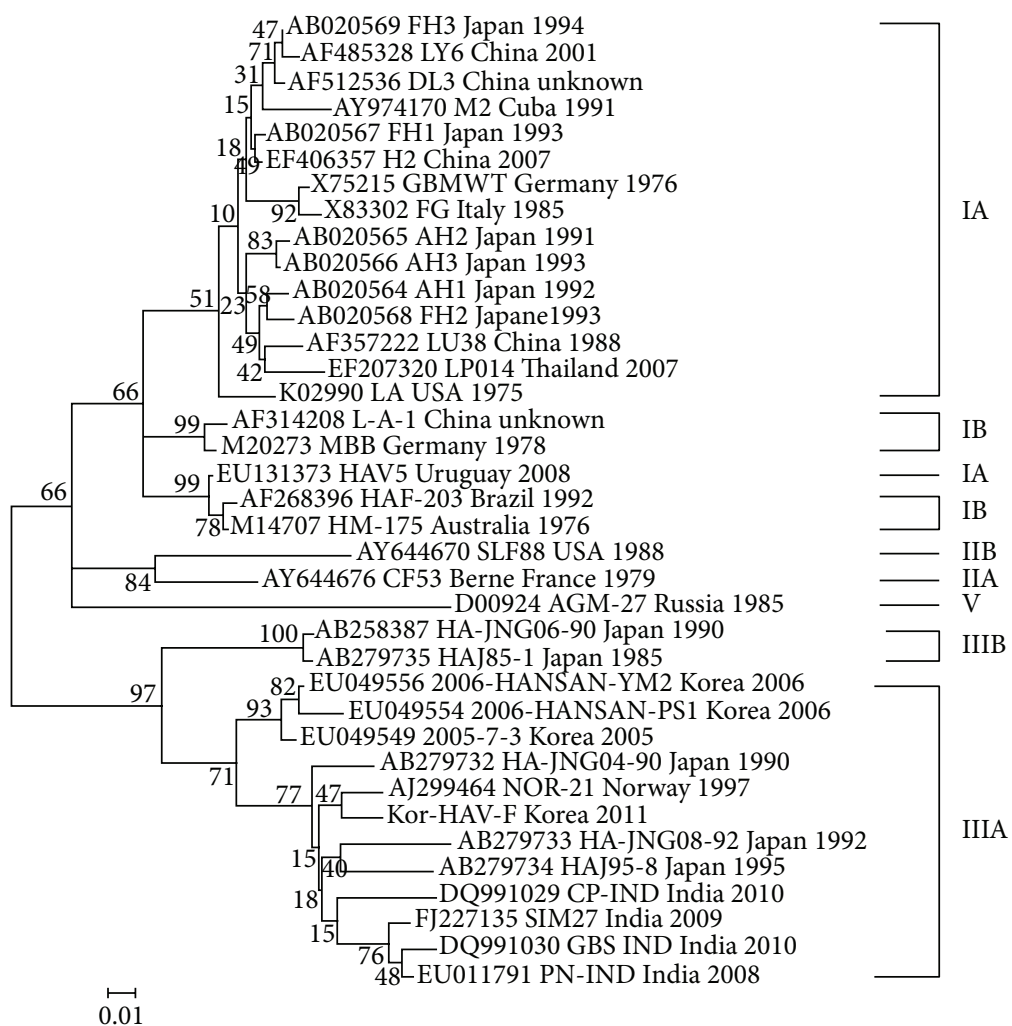

(a)

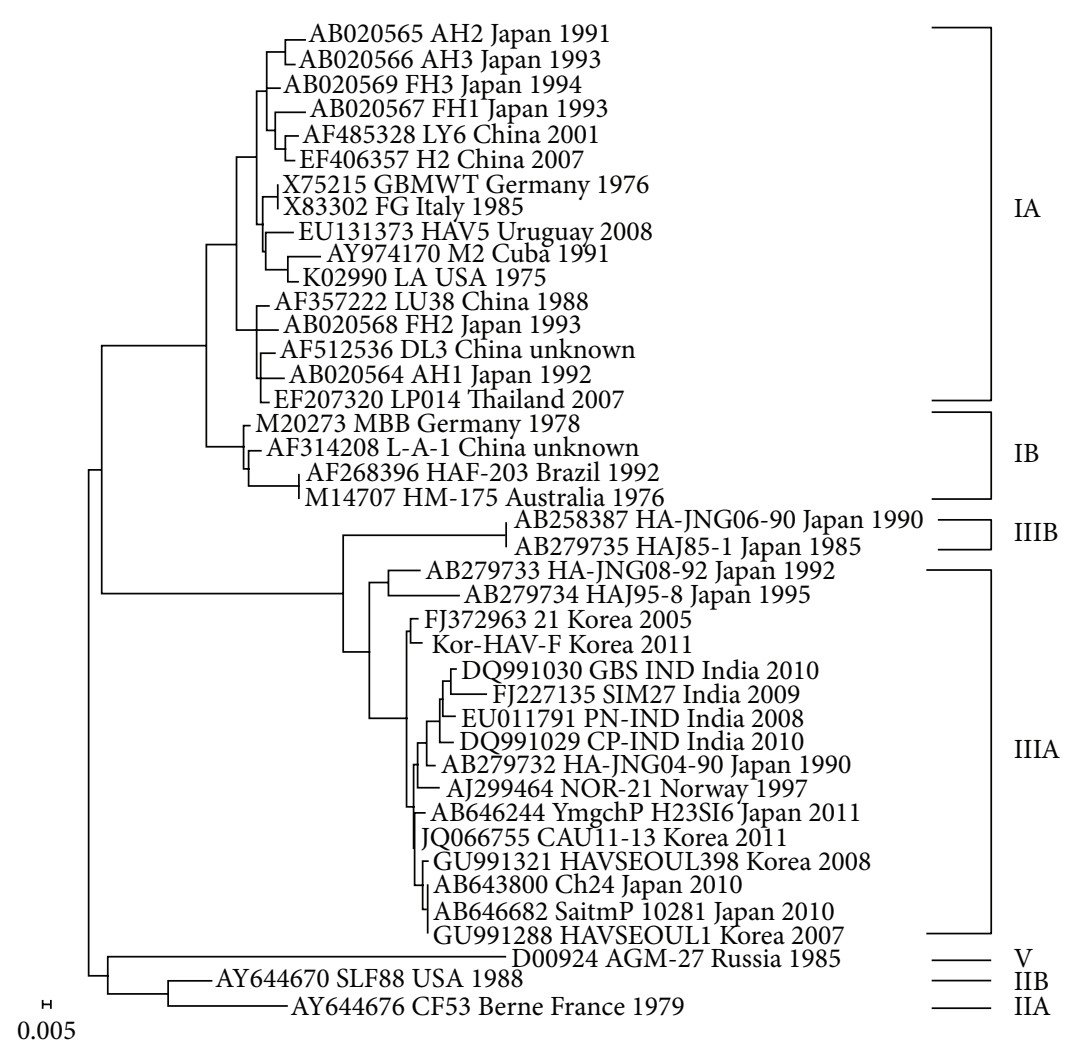

(b)

Figure 2: Phylogenetic trees of the nucleotide sequences of HAVs. The phylogenetic tree analysis was based on the nucleotide sequences of the VP3/VP1 (a) and VP1/2A (b) regions of the Kor-HAV-F and reference strains. 


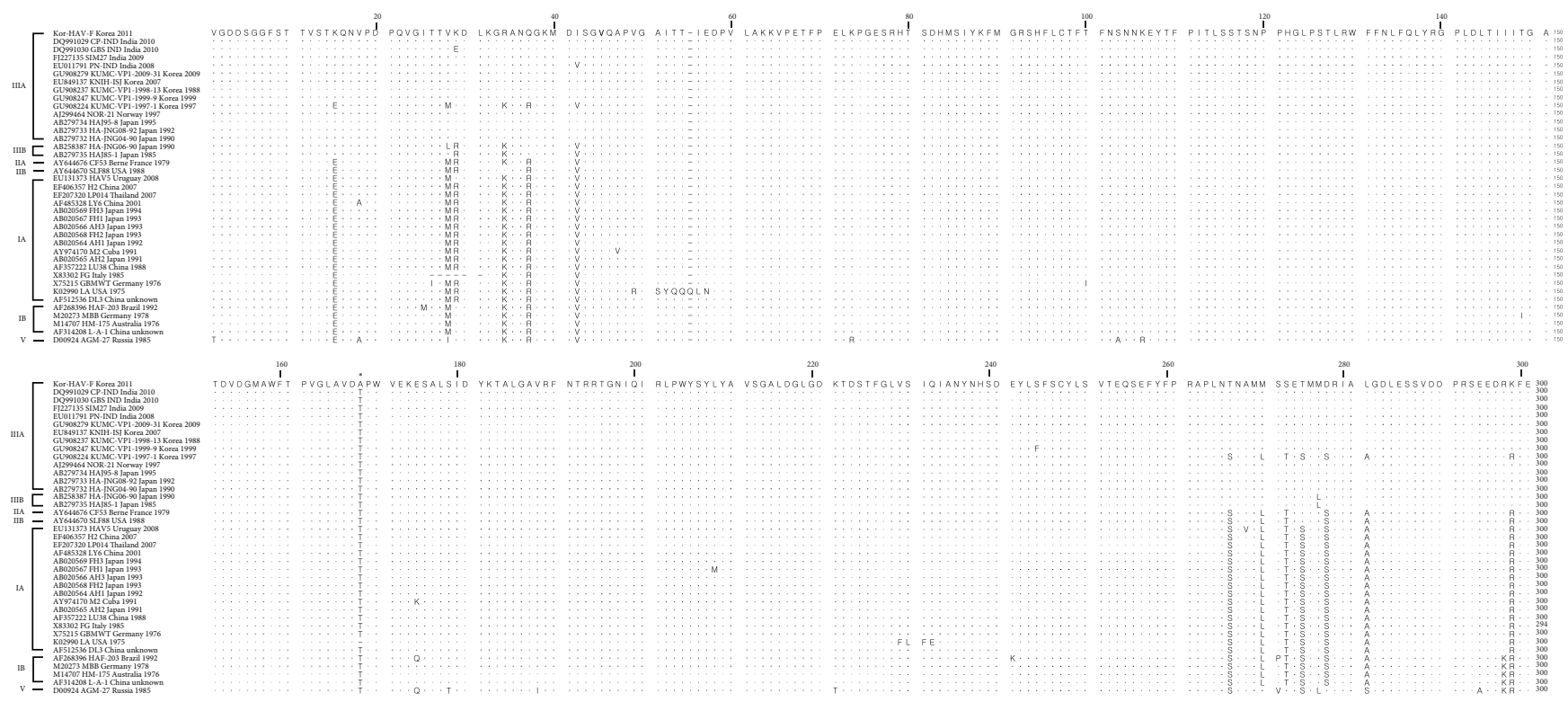

(a)

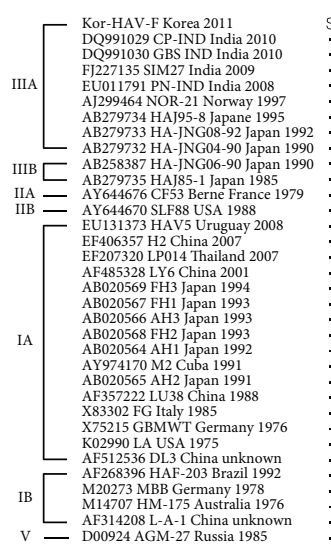

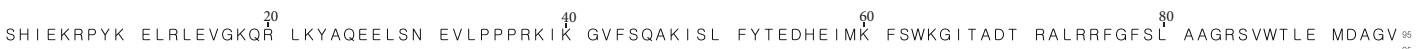
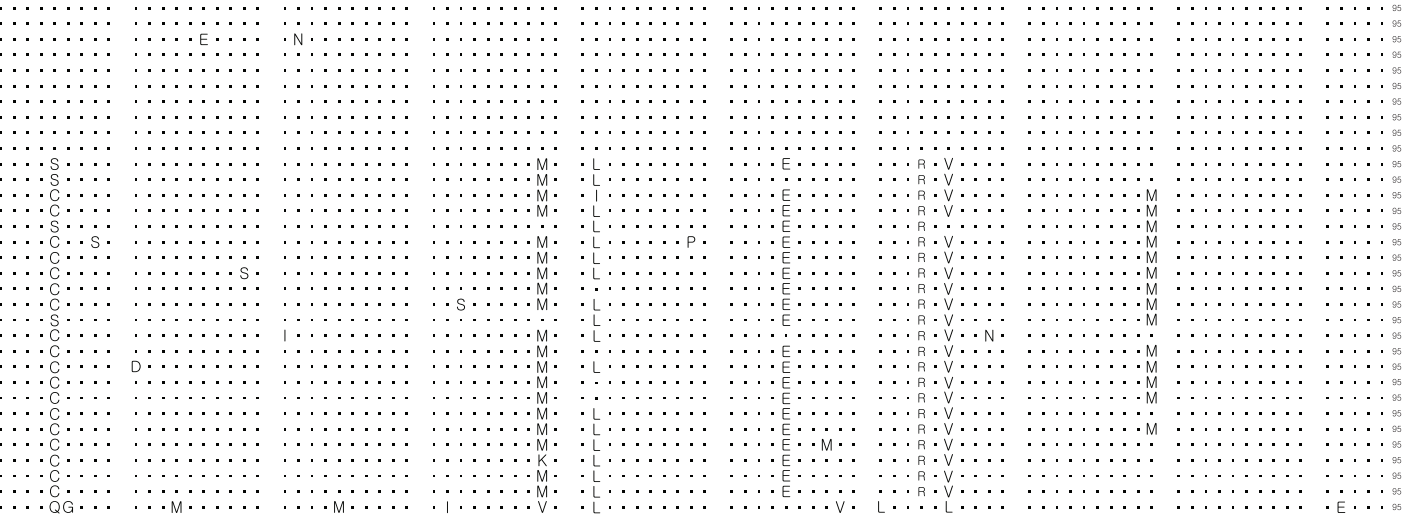

100

120

140

160

180
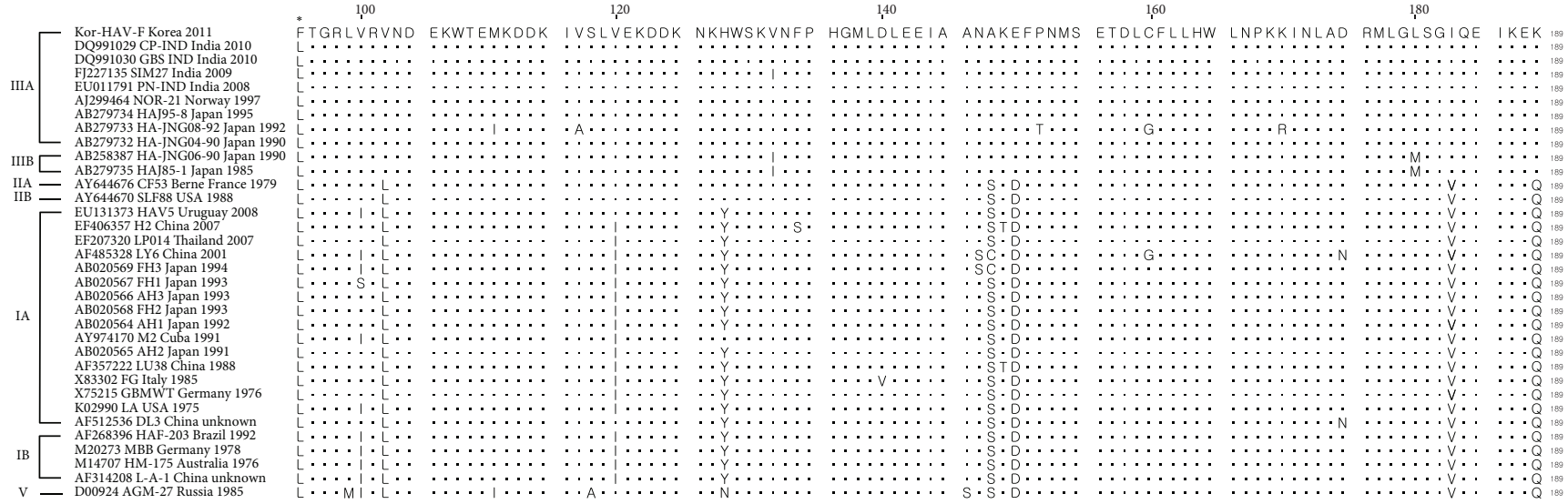

(b)

FIGURE 3: Alignment analysis of the VP1 (a) and 2A (b) regions of HAV strains (asterisk indicated mutation) Amino acid sequences of the VP1/2A region were compared with diverse subgenotype strains reported from various countries, including the Republic of Korea. 
improvements in sanitation and socioeconomic conditions; therefore, susceptible populations of the infection is changed to adolescents and young adults $[18,30,31]$.

Since 2001, the incidence of acute hepatitis was officially reported through the national sentine surveillance system of Korean Center for Disease Control and Prevention; after that, the incidence of acute hepatitis was increased steadily, and it was sharply raised from 2006 [32].

This is the first study reporting the full-length sequence of an HAV isolated in the Republic of Korea. This sequence will be useful for comparison with the full-length HAV sequences of other strains currently identified globally and in future. The whole-genome sequence data derived in this study may prove useful not only for more accurate diagnoses of HAV, but also for basic research relating to the elucidation of genetic functions. Furthermore, it may prove useful for the prediction of newly appearing variants via comparison with HAV strains worldwide, in fundamental research for vaccine development, and eventually, in the field of public health, with identification of new emerging strains of HAV.

\section{Conclusions}

This study, the first to report the full-length sequence of a $\mathrm{HAV}$ isolated in the Republic of Korea, is meaningful as it provides a full-length HAV sequence standard for future evolutionary studies. It may also prove useful in the field of public health by facilitating the diagnosis and predicting new emerging variants. Further characterization of fulllength sequences of diverse HAV strains circulating worldwide is needed.

\section{Conflict of Interests}

The authors declare that they have no conflict of interests.

\section{Acknowledgment}

This work was supported by a Mid-career Researcher Program (2012R1A2A2A01045078) through the NRF Grant funded by the MEST.

\section{References}

[1] K. H. Jacobsen and J. S. Koopman, "Declining hepatitis A seroprevalence: a global review and analysis," Epidemiology and Infection, vol. 132, no. 6, pp. 1005-1022, 2004.

[2] S. M. Lemon, "Type A viral hepatitis. New developments in an old disease," New England Journal of Medicine, vol. 313, no. 17, pp. 1059-1067, 1985.

[3] J. A. Cuthbert, "Hepatitis A: old and new," Clinical Microbiology Reviews, vol. 14, no. 1, pp. 38-58, 2001.

[4] J. L. Melnick, "Properties and classification of hepatitis A virus," Vaccine, vol. 10, supplement 1, pp. S24-S26, 1992.

[5] E. A. Brown, S. P. Day, R. W. Jansen, and S. M. Lemon, “The 5' nontranslated region of hepatitis A virus RNA: secondary structure and elements required for translation in vitro," Journal of Virology, vol. 65, no. 11, pp. 5828-5838, 1991.
[6] A. Totsuka and Y. Moritsugu, "Hepatitis A virus proteins," Intervirology, vol. 42, no. 2-3, pp. 63-68, 1999.

[7] B. H. Robertson, R. W. Jansen, B. Khanna et al., "Genetic relatedness of hepatitis A virus strains recovered from different geographical regions," Journal of General Virology, vol. 73, no. 6, pp. 1365-1377, 1992.

[8] L. Lu, K. Z. Ching, V. S. de Paula et al., "Characterization of the complete genomic sequence of genotype II hepatitis A virus (CF53/Berne isolate)," Journal of General Virology, vol. 85, no. 10, pp. 2943-2952, 2004.

[9] M. H. Kim, H. Choi, K. S. Pak, C. N. Seong, and H. W. Cho, "Characterization of acute hepatitis virus A genotype in Korea," Journal of Life Science, vol. 23, no. 2, pp. 175-181, 2013.

[10] O. V. Nainan, G. Xia, G. Vaughan, and H. S. Margolis, "Diagnosis of hepatitis A virus infection: a molecular approach," Clinical Microbiology Reviews, vol. 19, no. 1, pp. 63-79, 2006.

[11] K. Stene-Johansen, T. Ø. Jonassen, and K. Skaug, "Characterization and genetic variability of Hepatitis A virus genotype IIIA," Journal of General Virology, vol. 86, no. 10, pp. 2739-2745, 2005.

[12] M. Costa-Mattioli, V. Ferre, S. Monpoeho et al., "Genetic variability of hepatitis A virus in South America reveals heterogeneity and co-circulation during epidemic outbreaks," Journal of General Virology, vol. 82, no. 11, pp. 2647-2652, 2001.

[13] M. Costa-Mattioli, S. Monpoeho, C. Schvoerer et al., "Genetic analysis of hepatitis A virus outbreak in France confirms the co-circulation of subgenotypes Ia, Ib and reveals a new genetic lineage," Journal of Medical Virology, vol. 65, no. 2, pp. 233-240, 2001.

[14] L. M. Villar, L. M. Morais, R. Aloise et al., "Co-circulation of genotypes IA and IB of hepatitis A virus in Northeast Brazil," Brazilian Journal of Medical and Biological Research, vol. 39, no. 7, pp. 873-881, 2006.

[15] J. Cristina and M. Costa-Mattioli, "Genetic variability and molecular evolution of Hepatitis A virus," Virus Research, vol. 127, no. 2, pp. 151-157, 2007.

[16] R. M. Pintó, D. Alegre, A. Domíngueza et al., "Hepatitis A virus in urban sewage from two Mediterranean countries," Epidemiology and Infection, vol. 135, no. 2, pp. 270-273, 2007.

[17] A. Normann, S. Badur, D. Önel et al., "Acute hepatitis A virus infection in Turkey," Journal of Medical Virology, vol. 80, no. 5, pp. 785-790, 2008.

[18] J.-H. Kim, "Recent epidemiological status and vaccination of hepatitis A in Korea," Journal of the Korean Medical Association, vol. 51, no. 2, pp. 110-118, 2008.

[19] S. Pina, M. Buti, R. Jardí, P. Clemente-Casares, J. Jofre, and R. Girones, "Genetic analysis of hepatitis A virus strains recovered from the environment and from patients with acute hepatitis," Journal of General Virology, vol. 82, no. 12, pp. 2955-2963, 2001.

[20] T. Mitsui, Y. Tsukamoto, A. Hirose et al., "Distinct changing profiles of hepatitis $\mathrm{A}$ and $\mathrm{E}$ virus infection among patients with acute hepatitis, patients on maintenance hemodialysis and healthy individuals in Japan," Journal of Medical Virology, vol. 78, no. 8, pp. 1015-1024, 2006.

[21] K. Endo, J. Inoue, M. Takahashi et al., "Analysis of the full-length genome of a subgenotype IIIB hepatitis A virus isolate: primers for broadly reactive PCR and genotypic analysis," Journal of Medical Virology, vol. 79, no. 1, pp. 8-17, 2007.

[22] Y. K. Yoon, B. C. Chun, H. K. Lee et al., "Epidemiological and genetic analysis of a sustained community-wide outbreak of hepatitis A in the Republic of Korea, 2008: a hospital-based case-control study," Journal of Clinical Virology, vol. 46, no. 2, pp. 184-188, 2009. 
[23] A. Totsuka and Y. Moritsugu, "Hepatitis A vaccine development in Japan," in Viral Hepatitis and Liver Disease, K. Nishioka, H. Suzuki, S. Mishiro, and T. Oda, Eds., pp. 509-513, Springer, Tokyo, Japan, 1994.

[24] Y. K. Yoon, J. E. Yeon, J. H. Kim et al., "Comparative analysis of disease severity between genotypes IA and IIIA of hepatitis A virus," Journal of Medical Virology, vol. 83, no. 8, pp. 1308-1314, 2011.

[25] H. Yun, S. Kim, H. Lee et al., "Genetic analysis of HAV strains isolated from patients with acute hepatitis in Korea, 2005-2006," Journal of Medical Virology, vol. 80, no. 5, pp. 777-784, 2008.

[26] H. U. Song, S. G. Hwang, C.-I. Kwon et al., "Molecular epidemiology of hepatitis A virus in the south-east area of Gyeonggido in Korea," Yonsei Medical Journal, vol. 50, no. 4, pp. 512-516, 2009.

[27] K. S. Byun, J. H. Kim, K. J. Song et al., "Molecular epidemiology of hepatitis A virus in Korea," Journal of Gastroenterology and Hepatology, vol. 16, no. 5, pp. 519-524, 2001.

[28] K.-O. Lee, S.-J. Jeong, H.-S. Seong et al., "Genetic analysis of hepatitis A virus isolated from Korea," Journal of Bacteriology and Virology, vol. 39, no. 3, pp. 165-171, 2009.

[29] H. Lee, H. Jeong, H. Yun et al., "Genetic analysis of hepatitis A virus strains that induced epidemics in Korea during 20072009," Journal of Clinical Microbiology, vol. 50, no. 4, pp. 12521257, 2012.

[30] B. C. Lee and D. B. Lee, "Clinical observation of type A hepatitis in children," Korea Journal of Pediatrics, vol. 22, no. 3, pp. 213222, 1979.

[31] Center for Disease Control and Prevention (CDC), "Prevention of hepatitis A through active or passive immunization Practices (ACIP)," MMWR Recommendations and Reports, vol. 48, pp. 137, 1999.

[32] Y. K. Cho and B. C. Song, "Prevention of viral hepatitis and vaccination," Korean Journal of Internal Medicine, vol. 82, no. 2, pp. 123-133, 2012. 

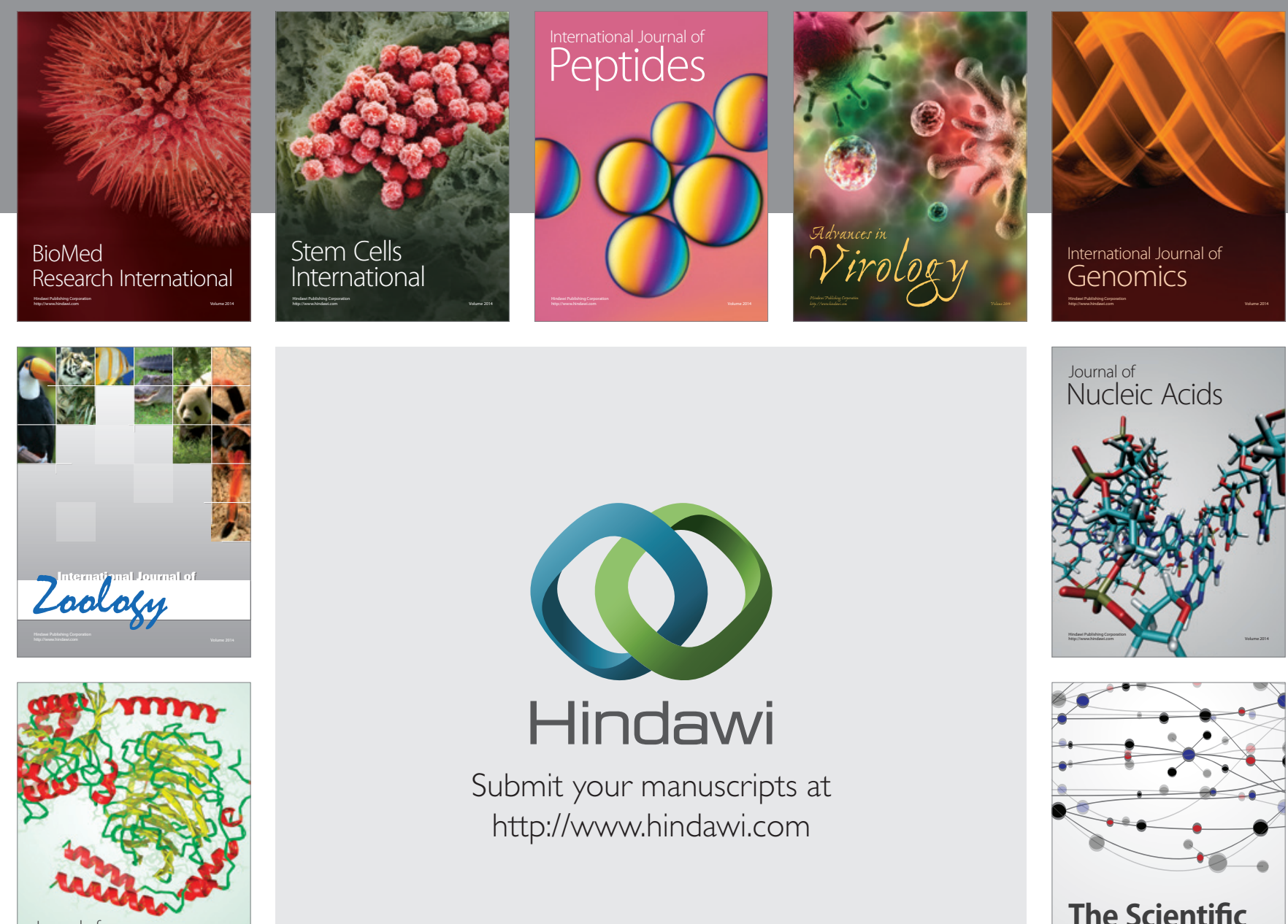

Submit your manuscripts at

http://www.hindawi.com

Journal of
Signal Transduction
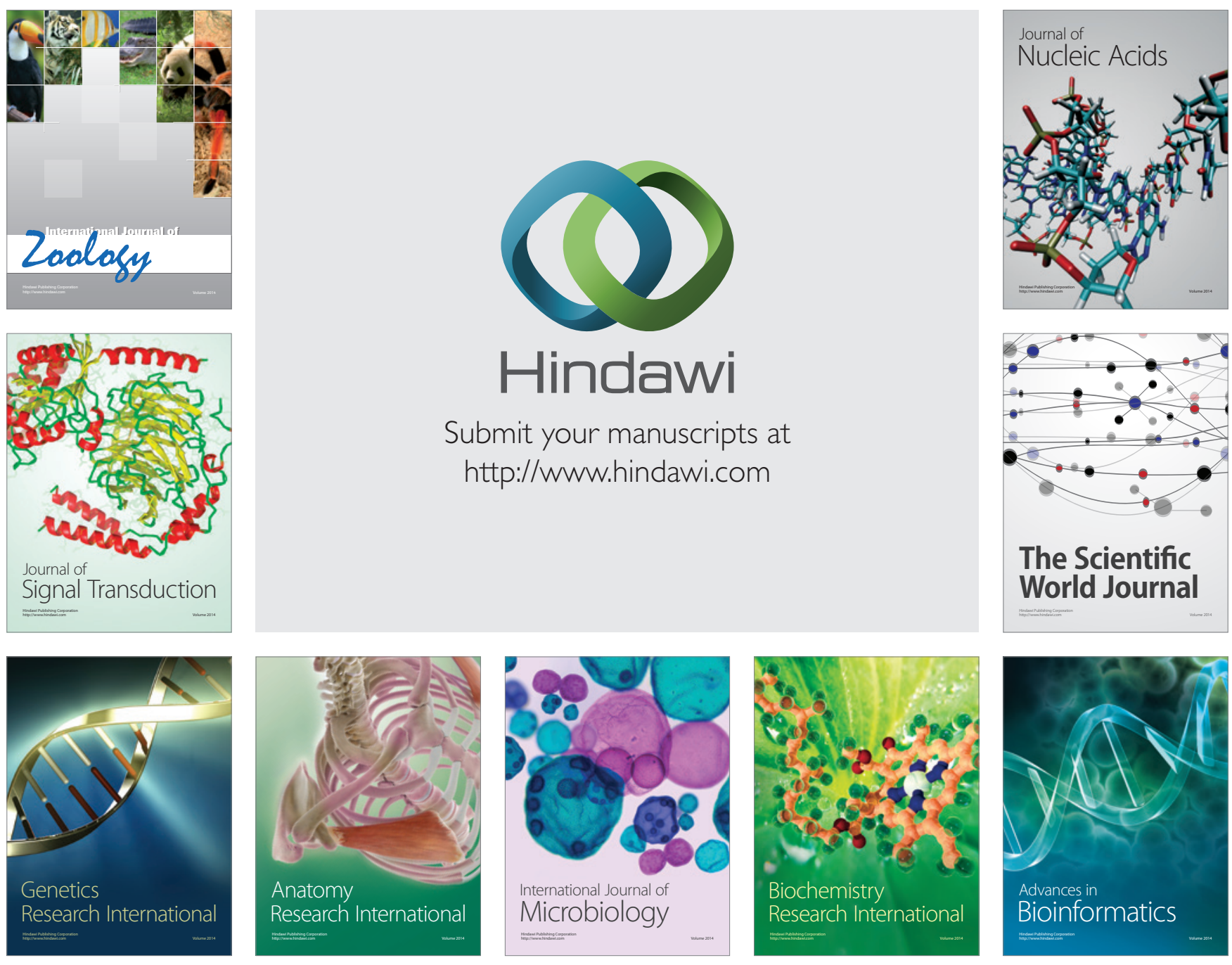

The Scientific World Journal
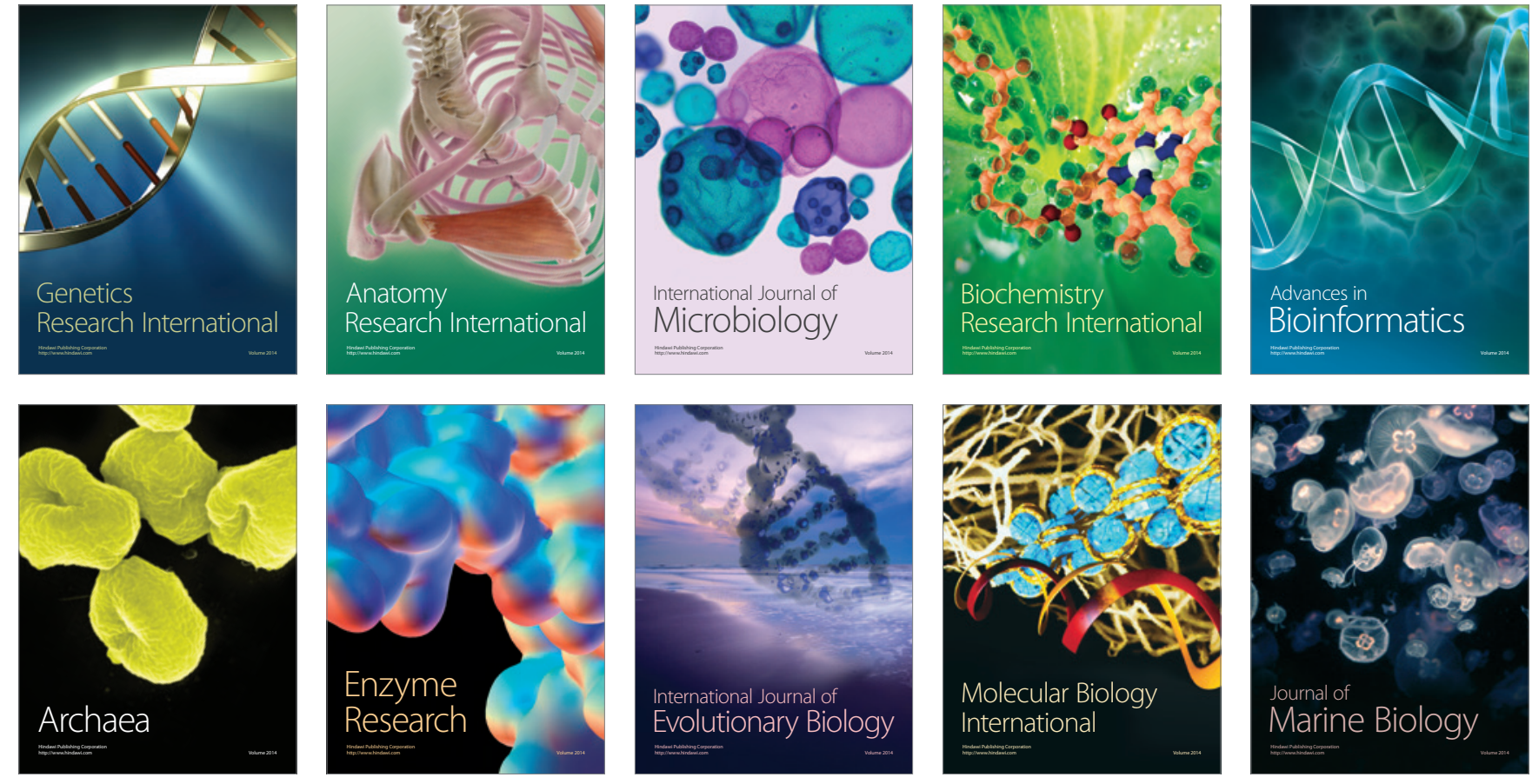